\title{
The accuracy of a new infrared ear thermometer in patients undergoing cardiac surgery
}

\section{[La précision d'un nouveau thermomètre auriculaire infrarouge chez des patients} de cardiochirurgie]

\author{
Matthias Bock MD DEAA, ${ }^{\star} \dagger$ Uta Hohlfeld, $\mathfrak{S}$ Kristine von Engeln MD, $\ddagger$ Peter A. Meier MD, $\$$ \\ Johann Motsch MD, ${ }^{*}$ Abel J. Tasman MD
}

\begin{abstract}
Purpose: To evaluate the equivalency of the prototype of a new infrared ear thermometer (IRT 4000) in comparison to the temperature measurements of a pulmonary artery catheter (PAC) and a continual contact probe on the tympanic membrane.

Methods: After approval by the local Ethics Committee, 26 (six female and 20 male) patients undergoing elective cardiac surgery were included in a single center open trial. During surgery, temperature measurements were recorded with the IRT 4000 in the left ear, and with a tympanic contact probe in the right ear, as well as with a PAC as reference. Measurements with the infrared ear thermometers and continual PAC values were recorded every six minutes.
\end{abstract}

Results: The average temperature measured with the IRT 4000 was $0.08^{\circ} \mathrm{C}$ above the temperature of the PAC $(95 \%$ confidence interval from $-0.44-0.61^{\circ} \mathrm{C}$ ).

Conclusion: Infrared ear thermometers 4000 temperature readings accurately reflect body core temperature and correlate well with the invasive PAC. Infrared ear thermometers may present a clinically useful alternative to the pulmonary artery thermometry for the measurement of core temperature in the perioperative setting or in the intensive care unit.

Objectif : Évaluer l'équivalence entre le prototype d'un nouveau thermomètre auriculaire infrarouge (IRT 4000), les mesures de température d'un cathéter de l'artère pulmonaire (CAP) et une sonde en contact permanent avec la membrane tympanique.

Méthode : Avec l'accord du Comité d'éthique, nous avons recruté 26 patients (6 femmes et 20 hommes), devant subir une intervention cardiaque réglée, pour une étude ouverte monocentrique. Pendant l'opération, la température a été mesurée avec le IRT 4000 dans l'oreille gauche et avec la sonde en contact avec le tympan dans l'oreille droite de même qu'avec le CAP comme point de référence. Les mesures faites avec les thermomètres infrarouges et les valeurs continues du CAP ont été enregistrées toutes les six minutes.

Résultats : La température moyenne mesurée avec le IRT 4000 $a$ été de $0,08{ }^{\circ} \mathrm{C}$ au-dessus de la température notée avec le CAP (intervalle de confiance de $95 \%$ de $-0,44-0,61^{\circ} \mathrm{C}$ ).

Conclusion: Les mesures des thermomètres infrarouges 4000 correspondent précisément à la température centrale du corps et sont en corrélation avec le CAP. Les thermomètres auriculaires infrarouges peuvent remplacer la thermométrie de l'artère pulmonaire pour mesurer la température centrale dans le contexte périopératoire ou à l'unité des soins intensifs.

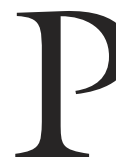

ERIOPERATIVE hypothermia is associated with numerous complications such as surgical wound infections, ${ }^{1}$ increased bleeding and transfusion requirements, ${ }^{2}$ morbid cardiac events $^{3}$ and increased costs of the perioperative management. ${ }^{4}$ Therefore, monitoring of body temperature is regarded as essential during anesthesia. ${ }^{5}$ Pulmonary artery thermometry reflects the temperature of the blood which supplies the vital organs and is often regarded as the "gold standard" for the measurement of core body temperature. ${ }^{6}$ However, it is generally accepted that none of the current thermometry methods is ideal, and the best anatomical measurement site alternative to the pulmonary artery has yet to be determined.

Temperature measured on the tympanic membrane correlates well with the temperature of the hypothala-

From the Departments of Anesthesiology, ${ }^{*}$ and Otorinolaryngology Head and Neck Surgery, $\ddagger$ University of Heidelberg, Heidelberg, Germany; the Department of Anesthesiology I, $†$ Zentralkrankenhaus Bozen, Bozen, Italy; and Braun GmbH, $\$$ Kronberg im Taunus, Germany.

Address correspondence to: Dr. Matthias Bock, Zentralkrankenhaus Bozen, Lorenz-Böhler-Str. 5, Bozen, Italy 39100. Phone: $++39-$

0471-908-673; Fax: ++39-0471-909-783; E-mail: matthias.bock@asbz.it

This work was sponsored by Braun GmbH, Frankfurter Strasse 145, 61476 Kronberg im Taunus, Germany.

Accepted for publication March 24, 2005.

Revision accepted June 23, 2005. 
mus because both the middle ear and the hypothalamic thermo integrating area are supplied by the common carotid artery. Infrared ear thermometers (IRT) were developed in the 1980's as a new non-invasive alternative measuring method. An IRT is a battery-operated unit which is inserted into the cartilaginous part of the auditory canal, without touching the osseous component or the tympanic membrane. An infrared sensor system detects the infrared emission of the ear drum and the medial aspects of the auditory canal, and displays readings within one second. Infrared thermometry might be of great interest in the intensive care unit or postoperative setting because it is rapid and not unpleasant for conscious patients. In addition, the risk of postoperative hypothermia is often ignored after regional anesthesia ${ }^{7}$ despite the fact that the duration of postoperative hypothermia is longer after regional anesthesia when compared to general anesthesia. ${ }^{8}$ Core temperature is monitored accurately in postoperative patients using electronic oral thermometers ${ }^{7}$ but the question remains to be answered, whether oxygen administration might influence oral temperature readings. ${ }^{9,10}$ Thus, accurate thermometry with an IRT would be of interest for both routine anesthesia practice and intensive care.

We therefore designed an open prospective study to determine whether IRT is an accurate and feasible method for thermometry in cardiac surgery patients. The study evaluated the performance of a new IRT prototype in comparison with pulmonary artery catheter thermometry and continuous tympanic membrane contact thermometry.

\section{Methods}

This open single-centre trial was conducted at the Heidelberg University Hospital. Eligible patients were classified according to American Society of Anesthesiologists physical status II and III, were between 18 to $85 \mathrm{yr}$ and scheduled for elective coronary artery bypass graft surgery.

The study was approved by the local Ethics Committee and all patients gave written informed consent to their participation in the trial, no later than the evening before the operation. Excluded were patients with an acute or chronic infection of the external auditory canal, the middle ear, the mastoid, and those with a congenital or acquired anomaly of the auditory canal as well as a defect of the tympanum, and impacted cerumen. In addition, patients with clinically significant microangiopathia, cerebral circulatory disease and migraine headaches were excluded. Infections in the external auditory canal or cerumen were excluded by preoperative otoscopy. Prior to induction of general anesthesia a tympanic membrane probe (Mon-a-therm ${ }^{\circledR}$ Tympanic, Tyco, HennefSieg, Germany) was placed gently on the tympanic membrane in the right auditory canal, until the patient felt a rubbing on the tympanic membrane. Then we isolated the aural canal with cotton. A pulmonary artery catheter (Swan Ganz catheter ${ }^{\circledR}$, Baxter Healthcare Co., Deerfield, IL, USA) was placed in all patients. Throughout the duration of anesthesia the infrared measurements of the tympanic temperature were recorded using a portable prototype IRT 4000 (Braun GmbH, Kronberg im Taunus, Germany). All single infrared measurements were recorded manually after the unit had been inserted in the outer third of the aural canal of the left ear. The temperature on the digital display was entered manually in the sheet for data registration.

The IRT 4000 uses a newly developed ExacTemp®- sensor (Braun $\mathrm{GmbH}$ ) measuring system with modified sensor technology, and a smaller measuring head optimized for reproducible measurements and reducing factors disturbing the measuring precision, such as cooling of the auditory canal due to the thermometer itself.

Measurements were recorded at six-minute intervals starting from the patients' arrival in the operation theatre. Each measurement period consisted of simultaneous recordings from the IRT 4000, the pulmonary artery catheter, and tympanic probe readings. Not more than five seconds after infrared thermometry, the readings of the pulmonary artery catheter and the tympanic probe were recorded. Ambient temperature and humidity were also recorded at 12-min intervals during the measuring period until the end of surgery. Temperatures during cardiopulmonary bypass were not included in the analysis because of absence or heterogeneity of pulmonary blood flow. In three patients measurements were terminated before the end of the operation due to the need of anesthetic interventions. All measurements and recordings were carried out by the same trial investigator.

The pulmonary artery catheter and the tympanic probe were labelled during the operation with the identification number of the corresponding patient. The tympanic probe was removed immediately after the end of surgery and stored. The pulmonary artery catheter was removed $12 \mathrm{hr}$ postoperatively and stored. These devices were validated postoperatively in a $40^{\circ} \mathrm{C}$ warm water bath (Haake DC 5, Thermo Haake $\mathrm{GmbH}$, Karlsruhe, Germany) using a reference thermometer (QuaT 100, Heraeus GmbH, Hanau, Germany). The IRT was defined as accurate throughout the experiment. Weekly tests in a black body 
heater (Thermo Scan BB 3200, ThermoScan Inc., San Diego, CA, USA) resulted in a mean value of the calibration error within the margin of $40 \pm 0.06^{\circ} \mathrm{C}$. The IRT was operated without offset, i.e., the exact temperature was recorded without a correction.

\section{Statistical analysis}

The data were analyzed according to the method published by Bland and Altman ${ }^{11}$ using the commercial software Medcalc (Medcalc, Dunkirchen, Belgium). In brief, paired data sets of two individual thermometry methods were compared with the mean value of these data and not to a reference method, to prevent exposure to a potential technical error. The mean value of the difference in methods was defined systemic error (bias). We calculated the 95\% confidence intervals $(\mathrm{CI})$ to report the repeatability (precision). A bias $>0.4^{\circ} \mathrm{C}$, and a $95 \% \mathrm{CI}> \pm 1.0^{\circ} \mathrm{C}$ was considered clinically significant.

\section{Results}

We enrolled 26 patients aged 48 to $81 \mathrm{yr}$ (median $67.5 \mathrm{yr}$ ). The median duration of all operations was $153 \mathrm{~min}$ (range 97-263 $\mathrm{min}$ ) with a median duration of the extracorporal circulation of $69.5 \mathrm{~min}$ (range 33-123 min). A total of 729 measurements were obtained. Twenty-two data sets were excluded because strong artefacts caused by bipolar high frequency coagulation interfered with the data registration of the IRT 4000, leaving 707 data sets for statistical analysis. These artefacts consisted of temperatures on the display which were obviously higher than the range of human thermoregulation. Per patient, a mean of 26.3 and a median of 23 measuring episodes (range 11-53) were included in the analysis. The temperatures evaluated in the calculations ranged from 33.6 to $37.6^{\circ} \mathrm{C}$. Ambient temperature ranged from 18.2 to $27.7^{\circ} \mathrm{C}$ which is within the range specified for the IRT 4000 $\left(10-40^{\circ} \mathrm{C}\right)$.

Relative to the pulmonary artery catheter, the agreement between measurements of the infrared thermometer IRT 4000 and those of the pulmonary artery catheter was $+0.08^{\circ} \mathrm{C}$, with a precision between 0.61 (upper 95\% CI) and -0.44 (lower 95\% CI; Figure 1). Relative to the tympanic contact probe, the agreement between measurements of the infrared thermometer IRT 4000 and those of the tympanic contact probe was $+0.22^{\circ} \mathrm{C}$, with a precision between 1.13 (upper 95\% CI) and -0.69 (lower 95\% CI; Figure 2).

\section{Discussion}

The aim of this trial was to examine the accuracy of infrared ear thermometry in comparison to pulmonary artery thermometry. All recorded temperatures

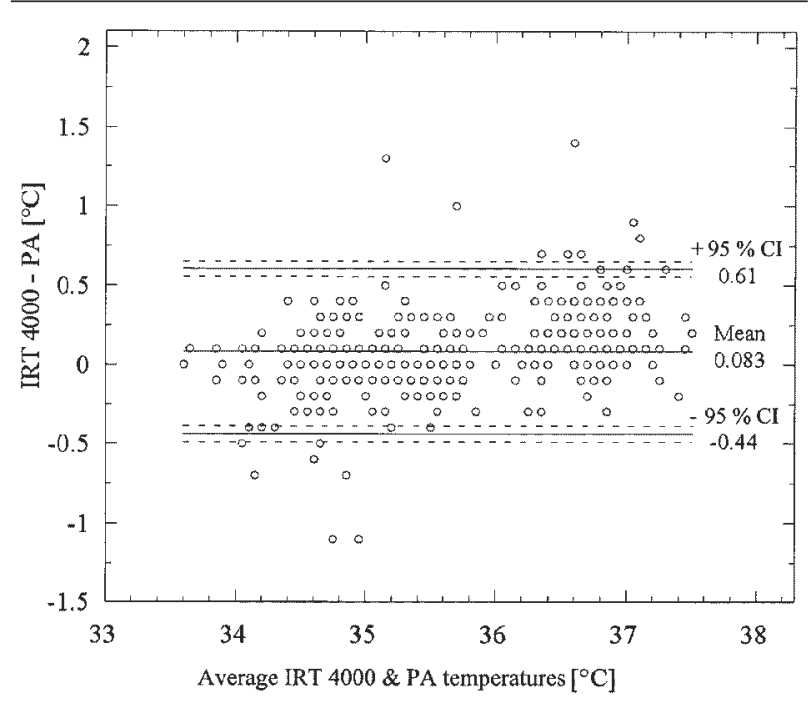

FIGURE 1 Bland Altman plot of the paired measurements displayed against the average of the pair when the prototype of the infrared ear thermometer (IRT 4000) was compared to the pulmonary artery $(\mathrm{PA})$ catheter.

lay within the range approved by the manufacturer of the IRT 4000 for the measurement of temperatures $\left(20-42.2^{\circ} \mathrm{C}\right)$. The results suggest potential suitability of IRT as an alternative to traditional methods of thermometry. Infrared tympanic thermometry is easy to learn and to perform, and training has little effect on the accuracy of the measurements ${ }^{12}$ which makes it a viable option for use in daily clinical practice. Because of its minimal invasiveness, infrared ear thermometry has gained popularity, especially in the pediatric field. However, one review stated that precision was insufficient if the temperature measured by IRT was compared to rectal thermometry. ${ }^{13}$ In adult perioperative patients, however, core temperature changes more rapidly so that the rectal temperature does not reflect the values measured by a pulmonary artery catheter. Due to its invasiveness, the pulmonary catheter is not indicated in the majority of surgical patients, so there is a clear need for a non-invasive thermometry method.

Prior to use in clinical practice, any new thermometry device should be validated in comparison to a generally accepted method such as thermometry of the pulmonary artery. In recent years, several studies on the accuracy of IRT have been published with conflicting results. ${ }^{14-23}$ We therefore evaluated the prototype in a population undergoing rapid changes in core temperature, using a large number 


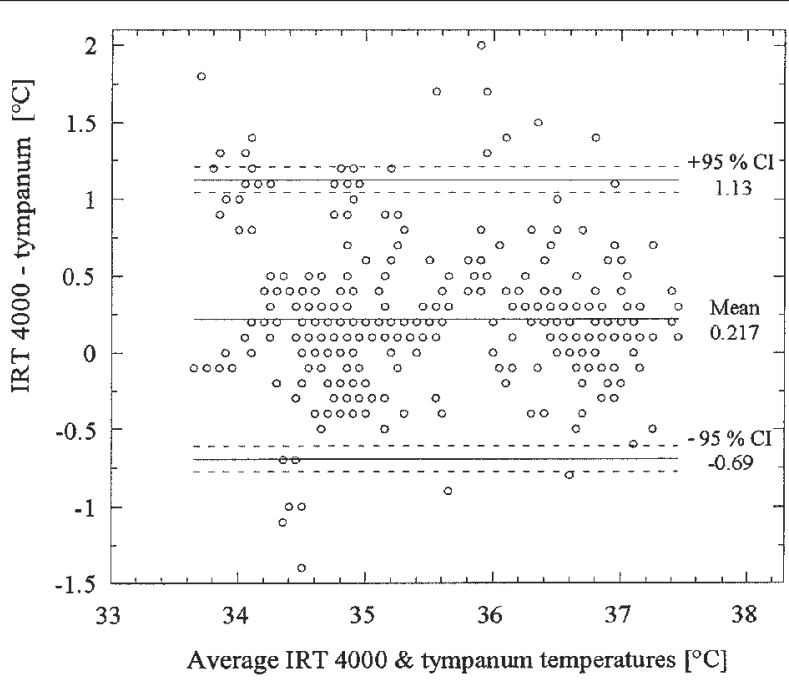

FIGURE 2 Bland Altman plot of the paired measurements plotted against the average of the pair when the prototype of the infrared ear thermometer IRT 4000 was compared to the tympanic membrane probe.

of measurements by an expert observer. In no previous study has such a large number of measurements been recorded with a single device. In several recent investigations rectal thermometry has been used as a gold standard. ${ }^{14,15}$ However, temperature changes in the rectum are relatively slow and do not always reflect the core temperature. This is especially true for patients under general or regional anesthesia who may develop rapid changes in core temperature. In other studies, pulmonary artery thermometry was preferred as the reference method. ${ }^{16-23}$ However, the statistical evaluation recommended by Bland and Altman ${ }^{11}$ was not used in all studies. ${ }^{16,17}$ This method considers that the result of any comparison of two instruments for clinical measurement can be due to technical errors in the reference method as well as in the new method to be tested. Therefore, the statistical analysis for comparing two methods of measurement should include this algorithm. ${ }^{21,24}$ Infrared ear thermometers tend to measure core temperatures exactly, or with slight underestimation among adults, when compared to blood temperature in the pulmonary artery. Our study demonstrates that an IRT is technically able to estimate core temperature with a low bias, as well as high reproducibility.

The results of our investigation also confirm previous studies in which infrared thermometry was compared with tympanic thermocouples during car- diac surgery, ${ }^{25}$ or amongst patients recovering from general and regional anesthesia. ${ }^{8}$ However, precision was unacceptable during cardiac surgery, ${ }^{25}$ which is at variance from observations in earlier studies. ${ }^{26}$ It is possible that the setting for cardiac surgery with limited access to the aural canal might interfere with the measurements when the thermometer's infrared collecting cylinder cannot be centred exactly towards the tympanum. We report a similar finding, as the reproducibility was greater when the IRT 4000 was compared to the pulmonary artery catheter, than with the tympanic thermocouple. It is important to note however, that the site of the measurement was identical for IRT and tympanic thermocouples, although the technology is completely different.

\section{Limitations of current investigation}

A previous study by Giuliano et al. ${ }^{20}$ distinguished between febrile and afebrile patients. In afebrile patients the bias of two thermistors were 0.09 (SD 0.7) and -0.19 (SD 0.64), respectively whereas among febrile patients a bias of -0.17 (SD 0.54) and - 0.05 (SD 0.65) was found. Due to our study design which evaluated patients during surgery and not in the intensive care unit, we have limited data on temperatures exceeding $37^{\circ} \mathrm{C}$. An evaluation of the performance of the IRT 4000 in septic patients would be of interest for further studies. As this was the first clinical evaluation of the IRT 4000, we also excluded the presence of obstruction or cerumen in the aural canal by preoperative otoscopy. This practice is clearly not applicable for routine use in the clinical setting. Consequently, we cannot provide data on the use of this prototype in the general population. Infrared thermometry readings might also be influenced by variations of cardiac output. ${ }^{22}$ We cannot provide data on this potential confounding variable, although we draw attention to the fact that the reading of each of the devices should be done simultaneously to augment the accuracy of the readings. Finally, we can exclude bias due to technical errors as all of our devices were controlled by the manufacturer and, moreover, we performed control data after the completion of the measurement in all patients.

In conclusion, we demonstrated that the IRT prototype IRT 4000 offers an accurate estimate of core temperature in comparison to invasive pulmonary artery catheter thermometry and contact measurement on the tympanic membrane. A major advantage of the IRT 4000 compared to the pulmonary artery catheter is the non-invasive operation of the device. The IRT 4000 may therefore be used as an alternative to the pulmonary artery thermometry for the measurement of core temperature in the perioperative setting. 


\section{Acknowledgement}

We sincerely thank Dr. H. Bauer, Department of Anesthesiology, University of Heidelberg for performing statistical analysis.

\section{References}

1 Kurz A, Sessler DI, Lenhardt R. Perioperative normothermia to reduce the incidence of surgical wound infection and shorten hospitalization. Study of Wound Infection and Temperature Group. N Engl J Med 1996; 334: 1209-15.

2 Schmied H, Kurz A, Sessler DI, Kozek S, Reiter A. Mild hypothermia increases blood loss and transfusion requirements during total hip arthroplasty. Lancet 1996; 347: 289-92.

3 Frank SM, Feisher LA, Breslow MJ, et al. Perioperative maintenance of normothermia reduces the incidence of morbid cardiac events. A randomized clinical trial. JAMA 1997; 277: 1127-34.

4 Bock M, Muller J, Bach A, Bohrer H, Martin E, Motsch $J$. Effects of preinduction and intraoperative warming during major laparotomy. Br J Anaesth 1998; 80: 159-63.

5 Bubre W, Roissant R. Perioperative management and monitoring in anaesthesia. Lancet 2003; 362: 183946.

6 Brengelmann GL. Body temperature regulation. In: Patton HD, Fuchs AF, Hille B, et al. (Eds). Textbook of Physiology, 21st ed. Philadelphia: WB Saunders Company; 1989: 1584-96.

7 Frank SM, Nguyen JM, Garcia CM, Barnes RA. Temperature monitoring practices during regional anesthesia. Anesth Analg 1999; 88: 373-7.

8 Cattaneo CG, Frank SM, Hesel TW, El-Rabmany HK, Kim LJ, Tran KM. The accuracy and precision of body temperature monitoring methods during regional and general anesthesia. Anesth Analg 2000; 90: 938-45.

9 Lim-Levy F. The effect of oxygen inhalation on oral temperature. Nurs Res 1982; 31: 150-2.

10 Yonkman CA. Cool and heated aerosol and the measurement of oral temperature. Nurs Res 1982; 31: 354-7.

11 Bland JM, Altman DG. Statistical methods for assessing agreement between two methods of clinical measurement. Lancet 1986; I: 307-10.

12 Petersen MH, Hauge HN. Can training improve the results with infrared tympanic thermometers? Acta Anaesthesiol Scand 1997; 41: 1066-70.

13 Craig JV, Lancaster GA, Taylor S, Williamson PR, Smyth $R L$. Infrared ear thermometry compared with rectal thermometry in children: a systematic review. Lancet 2002; 360: 603-9.

14 Petersen-Smith A, Barber N, Coody DK, West MS,
Yetman RJ. Comparison of aural infrared with traditional rectal temperatures in children from birth to age three years. J Pediatr 1994; 125: 83-5.

15 Talo H, Macknin ML, VanderBrug Medendorp S. Tympanic membrane temperatures compared to rectal and oral temperatures. Clin Pediatr 1991; 30(Suppl): 30-3.

16 Klein DG, Mitchell C, Petrinec A, et al. A comparison of pulmonary artery, rectal, and tympanic membrane temperature measurement in the ICU. Heart Lung 1993; 22: 435-41.

17 Erickson RS, Meyer LT. Accuracy of infrared ear thermometry and other temperature methods in adults. Am J Crit Care 1994; 3: 40-54.

18 Stavem K, Saxholm H, Smith-Erichsen N. Accuracy of infrared ear thermometry in adult patients. Intensive Care Med 1997; 23: 100-5.

19 Robinson J, Charlton J, Seal R, Spady D, Joffres MR. Oesophageal, rectal, axillary, tympanic and pulmonary temperatures during cardiac surgery. Can J Anaesth 1998; 45: 317-23.

20 Giuliano KK, Giuliano AJ, Scott SS, et al. Temperature measurement in critically ill adults: a comparison of tympanic and oral methods. Am J Crit Care 2000; 9: 254-61.

21 Giuliano KK, Scott SS, Elliot S, Giuliano AJ. Temperature measurement in critically ill orally intubated adults: a comparison of pulmonary artery core, tympanic, and oral methods. Crit Care Med 1999; 27: 2188-93.

22 Rotello LC, Crawford L, Terndrup TE. Comparison of infrared ear thermometer derived and equilibrated rectal temperatures in estimating pulmonary artery temperatures. Crit Care Med 1996; 24: 1501-6.

23 Erickson RS, Kirklin SK. Comparison of ear-based, bladder, oral, and axillary methods for core temperature measurement. Crit Care Med 1993; 21: 1528-34.

24 Mantha S, Roizen MF, Fleisher LA, Thisted R, Foss J. Comparing methods of clinical measurement: reporting standards for Bland and Altman analysis. Anest Analg 2000; 90: 593-602.

25 Imamura M, Matsukawa T, Ozaki M, Sessler DI, Nishiyama T, Kumazawa T. The accuracy and precision of four infrared aural canal thermometers during cardiac surgery. Acta Anaesthesiol Scand 1998; 42: 1222-6.

26 Matsukawa T, Ozaki M, Hanagata K, Iwashita $H$, Miyaji T, Kumazawa T. A comparison of four infrared tympanic thermometers with tympanic membrane temperatures measured by thermocouples. Can J Anaesth 1996; 43: 1224-8. 